\title{
The clinical spectrum of severe childhood malaria in Eastern Uganda
}

Peter Olupot-Olupot ${ }^{1,2^{*}}$, Charles Engoru ${ }^{3}$, Julius Nteziyaremye ${ }^{1,2}$, Martin Chebet ${ }^{1,2}$, Tonny Ssenyondo ${ }^{2}$, Rita Muhindo ${ }^{2}$, Gideon Nyutu ${ }^{4}$, Alexander W. Macharia ${ }^{4}$, Sophie Uyoga ${ }^{4}$, Carolyne M. Ndila ${ }^{4}$, Charles Karamagi ${ }^{5}$, Kathryn Maitland ${ }^{4,6}$ and Thomas N. Williams ${ }^{4,6}$ (D)

\begin{abstract}
Background: Few recent descriptions of severe childhood malaria have been published from high-transmission regions. In the current study, the clinical epidemiology of severe malaria in Mbale, Eastern Uganda, is described, where the entomological inoculation rate exceeds 100 infective bites per year.

Methods: A prospective descriptive study was conducted to determine the prevalence, clinical spectrum and outcome of severe Plasmodium falciparum malaria at Mbale Regional Referral Hospital in Eastern Uganda. All children aged 2 months-12 years who presented on Mondays to Fridays between 8.00 am and 5.00 pm from 5th May 2011 until 30th April 2012 were screened for parasitaemia. Clinical and laboratory data were then collected from all P. falciparum positive children with features of WHO-defined severe malaria by use of a standardized proforma.

Results: A total of 10208 children were screened of which 6582 (64\%) had a positive blood film. Of these children, $662(10 \%)$ had clinical features of severe malaria and were consented for the current study. Respiratory distress was the most common severity feature (554; 83.7\%), while 365/585 (62.4\%) had hyperparasitaemia, 177/662 (26.7\%) had clinical jaundice, 169 (25.5\%) had severe anaemia, 134/660 (20.2\%) had hyperlactataemia (lactate $\geq 5$ mmol/L), 93 (14.0\%) had passed dark red or black urine, 52 (7.9\%) had impaired consciousness and 49/662 (7.4\%) had hypoxaemia (oxygen saturations $<90 \%$ ). In-hospital mortality was 63/662 (9.5\%) overall but was higher in children with either cerebral malaria (33.3\%) or severe anaemia (19.5\%). Factors that were independently associated with mortality on multivariate analysis included severe anaemia [odds ratio (OR) 5.36; 2.16-1.32; $P=0.0002$ ], hyperlactataemia (OR 3.66; $1.72-7.80 ; P=0.001$ ), hypoxaemia (OR) 3.64 (95\% Cl 1.39-9.52; $P=0.008)$, and hepatomegaly (OR 2.29; 1.29-4.06; $P=0.004)$. No independent association was found between mortality and either coma or hyperparasitaemia.
\end{abstract}

Conclusions: Severe childhood malaria remains common in Eastern Uganda where it continues to be associated with high mortality. An unusually high proportion of children with severe malaria had jaundice or gave a history of having recently passed dark red or black urine, an issue worthy of further investigation.

Keywords: Severe malaria, Severe anaemia, Dark red or black urine, P. falciparum malaria, Children, Uganda

*Correspondence: polupotolupot@yahoo.com

${ }^{\dagger}$ Kathryn Maitland, Thomas N. Williams equal contributed

${ }^{1}$ Faculty of Health Sciences, Busitema University, Mbale Campus, P.O. Box 1460, Mbale, Uganda

Full list of author information is available at the end of the article

\section{Background}

Despite the recent control strategies of national and international communities, Plasmodium falciparum malaria remains a major cause of morbidity and mortality in tropical countries, especially within the WHO Africa Region which accounts for the majority of cases worldwide [1]. According to the latest World Health

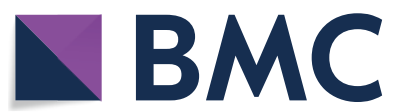

(c) The Author(s) 2020. This article is licensed under a Creative Commons Attribution 4.0 International License, which permits use, sharing, adaptation, distribution and reproduction in any medium or format, as long as you give appropriate credit to the original author(s) and the source, provide a link to the Creative Commons licence, and indicate if changes were made. The images or other third party material in this article are included in the article's Creative Commons licence, unless indicated otherwise in a credit line to the material. If material is not included in the article's Creative Commons licence and your intended use is not permitted by statutory regulation or exceeds the permitted use, you will need to obtain permission directly from the copyright holder. To view a copy of this licence, visit http://creativeco mmons.org/licenses/by/4.0/. The Creative Commons Public Domain Dedication waiver (http://creativecommons.org/publicdomain/ zero/1.0/) applies to the data made available in this article, unless otherwise stated in a credit line to the data. 
Organization (WHO) report, six countries accounted for more than half of all malaria cases worldwide in 2018: Nigeria (25\%), the Democratic Republic of the Congo (12\%), Uganda (5\%), and Côte d'Ivoire, Mozambique and Niger (4\% each) [1].

In Uganda, the most recent descriptive studies of severe malaria, conducted in the central, south-western and south-eastern parts of the country, were published more than 15 years ago $[2,3]$. Whereas the clinical spectrum of severe malaria that they described was broadly similar to that in previous studies $[4,5]$, the picture from the western part of the country was more consistent with descriptions from low transmission settings [6]. In recent years, a growing frequency of blackwater fever, a syndrome characterized by the triad of anaemia, jaundice and the passage of dark red or black urine, often associated with malaria parasitaemia [7], has been observed among children presenting to our hospital in Mbale in Eastern Uganda, a complication that has not featured strongly in previous descriptions of severe childhood malaria from Africa. The current study was conducted with the aim of providing a contemporary description of the clinical spectrum of severe childhood malaria in Eastern Uganda, and to identify the factors associated with mortality.

\section{Methods}

\section{Clinical and laboratory data}

We conducted a prospective descriptive study within the Paediatric Acute Care Unit (PACU) of Mbale Regional Referral Hospital (MRRH) between $5^{\text {th }}$ May 2011 and 30th April 2012. MRRH is a 470-bed hospital with 95 paediatric beds that is situated in a region of Eastern Uganda with hyper-endemic malaria transmission [8]. All children presenting to MRRH with acute illnesses are admitted to the PACU for $24 \mathrm{~h}$, which generally receives approximately 17000 admissions per year. All children aged 2 months to 12 years who were admitted to PACU between 8:00 am and 5:00 pm from Mondays to Fridays were screened for malaria, and all those who had both a positive $P$. falciparum blood film and one or more clinical or laboratory features of WHO-defined severe malaria were recruited [6, 9-12] (Table 1).

Standard case report forms (CRFs) were used to collect data on clinical, laboratory and socio-demographic factors, along with subsequent treatment and outcome. Patients displaying any of the following clinical features were recruited if their peripheral blood smears were positive for asexual forms of $P$. falciparum. Impaired consciousness was defined as prostration (generalized weakness so that the patient was unable walk or sit up without assistance) or coma (an unarousable state with a corresponding Blantyre Coma Scale $(B C S) \leq 2$ ) where no other cause other than malaria could be identified. Multiple convulsions, defined as $>2$ episodes in the $24 \mathrm{~h}$ period prior to admission. Respiratory distress was defined as increased work of breathing manifesting as deep, fast or very slow breathing, including retractions and the use of accessory muscles. Spontaneous bleeding was defined as physically un-induced and irrepressible bleeding from at least two non-traumatized sites in a

Table 1 Criteria used as indicators of severe malaria in the study

\begin{tabular}{|c|c|}
\hline Clinical criteria & Definition \\
\hline Clinical jaundice & Yellow mucous membranes noted in sufficient daylight \\
\hline Respiratory distress & $\begin{array}{l}\text { Increased work of breathing, manifesting as deep, fast or very slow breathing, including retractions and the use of accessory } \\
\text { muscles }\end{array}$ \\
\hline Severe anaemia & Haemoglobin $<5 \mathrm{~g} / \mathrm{dL}$ \\
\hline Prostration & Generalized weakness so that the patient is unable walk or sit up without assistance \\
\hline Coma & $\begin{array}{l}\text { Unrousable state with a corresponding Blantyre Coma Score (BCS) of } \leq 2 \text { for which no other cause other than malaria could be } \\
\text { identified }\end{array}$ \\
\hline Haemoglobinuria & History of or clinician-observed red or cola-coloured urine \\
\hline Multiple convulsions & More than two grand-mal seizures during the 24 -h period preceding admission \\
\hline Spontaneous bleeding & $\begin{array}{l}\text { Physically un-induced and irrepressible bleeding from at least } 2 \text { non-traumatized sites in a patient with severe malaria without } \\
\text { previous history of abnormal bleeding }\end{array}$ \\
\hline \multicolumn{2}{|l|}{ Laboratory criteria } \\
\hline Hyperlactataemia & Lactate $>5 \mathrm{mmol} / \mathrm{L}$ \\
\hline Hyperparasitaemia & $>5 \%$ parasitized erythrocytes or $>250000$ parasites/ $\mu \mathrm{L}$ \\
\hline Hyperpyrexia & Axillary temperature $\geq 40.0^{\circ} \mathrm{C}$ \\
\hline Hypoxaemia & Oxygen saturation $<90 \%$ \\
\hline Hypoglycaemia & Whole blood glucose concentration $<2.2 \mathrm{mmol} / \mathrm{L}$ \\
\hline Metabolic acidosis & Plasma bicarbonate $<15 \mathrm{mmol} / \mathrm{L}$ \\
\hline
\end{tabular}


patient with severe malaria without a previous history of abnormal bleeding. Haemoglobinuria was defined when the parent reported a history of, and the clinician macroscopically observed, dark red or black urine according to a score of 5 or more on the Hillman urine colour scale [13], a description that is more objective than a history of passing dark red or black urine alone that was previously used in the Democratic Republic of Congo (DRC) [14, 15], Nigeria [16] and Burundi [17]. Clinical jaundice was defined as the yellowing of mucous membranes noted in sufficient daylight. Pyrexia was defined as an axillary temperature of $>37.5{ }^{\circ} \mathrm{C}$, measured using a digital thermometer and hyperpyrexia as an axillary temperature of $\geq 40.0^{\circ} \mathrm{C}$. Hypoxaemia was defined as a transcutaneous oxygen saturation $\left(\mathrm{TCpO}_{2}\right)$ of $<90 \%$, as measured using a standard pulse oximeter. Definitions of laboratory criteria included: hypoglycaemia (blood glucose $<2.2 \mathrm{mmol} / \mathrm{L}$ ), metabolic acidosis (plasma bicarbonate $<15 \mathrm{mmol} / \mathrm{L})$, severe anaemia $(\mathrm{Hb}<5 \mathrm{~g} / \mathrm{dL})$, hyperparasitaemia $(>5 \%$ or $250000 / \mu \mathrm{L}$ ) [8], and hyperlactataemia (lactate $\geq 5 \mathrm{mmol} / \mathrm{L}$ ). On outcomes, a severe malaria death in our study was any in-hospital fatality in a child recruited to the study.

Eligible patients with any of the above features of severity were invited to participate after informed consent was sought from the patient's parent or guardian. Data were captured on a case report form (CRF), which was logically sequenced to capture data on: socio-demographic features, clinical features (symptoms and signs), laboratory data, treatment and outcome. Blood samples for the study were collected for parasitological microscopy as well as estimation of lactate using (ARKRAY Factory, Shiga, Japan), and random blood sugar levels using On Call Plus (ACON Laboratories, San Diego, USA). In addition, a small volume of blood was collected for additional tests including $2 \mathrm{mls}$ of whole blood for a complete blood count $(\mathrm{CBC})$ and $0.1 \mathrm{mls}$ for a quality-controlled blood slide. At the hospital, HIV testing was routinely done as part of the Ministry of Health policy.

\section{Malaria detection}

Initial thick and thin blood smears were made from finger prick blood samples for identification and typing of Plasmodium parasites. Blood smears were stained with $10 \%$ Giemsa, a stable methanol based Romanowsky stain, at pH 7.2. The stained blood smears were examined microscopically under $x 400$ and $x 1000$ objectives. The presence of Plasmodium parasites was noted based on their staining features. Malaria parasites were further quantified by examining microscopically under the $x 100$ objective. The number of Plasmodium parasites in the positive smears was counted against $500 \mathrm{WBCs}$ and the value that was obtained was multiplied by 16 in order to obtain the Plasmodium parasitaemia/ $\mu \mathrm{l}$ of whole blood.

\section{Case management}

All patient management at the PACU followed two protocols. First, the Emergency Triage and Treatment (ETAT) guidelines [18] were followed to triage all sick children on arrival into those with emergency signs, priority signs, or non-urgent cases and implementing emergency care. Second, once the emergency and priority cases had been stabilized, underlying causes for admission were treated following the Uganda National Treatment Guidelines 2010. These included but were not exclusive to antibiotic treatment for bacterial diseases such as pneumonia, meningitis, infective diarrhoea, sepsis, dysentery, and urinary tract infections. During the period of this study, anti-malarial treatment for severe malaria centred on IV quinine given intravenously at a dose of $10 \mathrm{mg} / \mathrm{kg}$ body weight in $10 \mathrm{mls}$ of $5 \%$ dextrose/ $\mathrm{kg}$ as a slow infusion over $4 \mathrm{~h}$ then repeating every $8 \mathrm{~h}$ until patients could tolerate oral medication in the same dose for a total of 7 days. Malaria presenting without features of severity was treated with the orally administered artemisinin-based combination antimalarial artemether/ lumefantrine, widely marketed as Coartem ${ }^{\circledR}$. When available, blood transfusion dosed at $20 \mathrm{mls}$ of whole blood/ $\mathrm{kg}$ was administered to children with severe anaemia. In addition, oxygen therapy was administered to patients with hypoxaemia. Hypoglycaemic patients were administered 25\% dextrose at a dose of $2 \mathrm{mls} / \mathrm{kg}$. Dehydration was treated with fluids according to the WHO protocols for moderate (Plan B) and severe (Plan C) dehydration. Referrals for specific care were made where appropriate, including to the Paediatric Infectious Diseases service for HIV infected children, the TB service for children with tuberculosis, the nutrition unit for malnourished children and physiotherapy for children requiring rehabilitation services. Temperature control with paracetamol and intermittent tepid sponging was administered to patients with temperatures of $>38.5^{\circ} \mathrm{C}$.

\section{Statistical analysis}

Categorical variables were compared by use of $x^{2}$ tests and continuous variables using Student's $t$-tests or ANOVA, as appropriate. Non-normally distributed variables were normalized by $\log _{10}$-transformation before analysis. P-values of $<0.05$ were considered statistically significant. Variables found to be significantly associated with mortality on univariate analysis were included in logistic regression models investigating independent predictors of mortality. All analyses were conducted using $R$ statistical software (http://www.R-project.org/). 


\section{Ethics and patient consent}

Written informed consent was provided by the parents or guardians of all study participants. Ethical permission for the study was granted by both the MRRH Research and Ethics Committee in Mbale and the Uganda National Council of Science and Technology (UNCST) in Kampala, both in Uganda.

\section{Results}

\section{Socio-demographic features}

A total of 10,208 children between 2 months and 12 years of age were admitted to the MRRH PACU during the period of data collection. Of these children, 6582 (64\%) had a positive blood film for $P$. falciparum malaria, of which $662(10 \%)$ had one or more clinical features of WHO-defined severe malaria and were included in the current study. Their median age was 18 (IQR $10-33)$ months while the majority $(603 / 662 ; 91.1 \%)$ were $<5$ years old (Table 2). All were residents of one of the 14 districts of the MRRH catchment area.

\section{Clinical features}

The clinical and laboratory characteristics of recruited children, stratified by survival to hospital discharge, are summarized in Table 2. Respiratory distress was observed in a high proportion (83.7\%) but was particularly common in those $<5$ years old $(92.6 \%)$. A lower proportion (7.9\%) showed signs of impaired consciousness while strictly defined cerebral malaria was rare (1.4\%). Decorticate, decerebrate or opisthotonic posturing was not observed in any of the cases. Overall, both clinical pallor (338; $51.1 \%$ ) and clinical jaundice $(177 ; 26.7 \%)$ were common. The recent passage of dark red or black urine was reported in $14.0 \%$, of whom a high proportion also had either clinical jaundice $(74.2 \%)$ or severe anaemia (43.0\%). Signs of impaired perfusion were seen in a high proportion: severe tachycardia in $53.7 \%$, a temperature gradient in $37.9 \%$ and a prolonged capillary refill time (CRT) in $20.4 \%$ (Table 2). More than one clinical or laboratory feature of severe malaria was seen in a high proportion of cases (Fig. 1).

\section{Laboratory characteristics}

The laboratory characteristics of recruited children are summarised in Table 3. Although parasite densities were high overall (geometric mean 58 800; 95\% CI 49700 69600 parasites $/ \mu \mathrm{L}$ ), densities of $<500$ parasites $/ \mu \mathrm{L}$ were seen in a small proportion (1.0\%). Severe anaemia was present in $25.5 \%$ of patients, most of whom were $<5$ years of age. A high proportion of severely anaemic children also manifested other clinical signs of severe malaria, including respiratory distress $(89.3 \%)$ and hyperlactataemia (40.2\%). Only $3.6 \%$ of children were hypoglycaemic.

\section{Outcome}

Overall mortality was $9.5 \%$, but this varied by clinical phenotype as summarized in Table 2 and Fig. 1. For example, although mortality was only $9.6 \%$ in children with respiratory distress, it was considerably higher $(33.3 \%)$ in children with cerebral malaria. Similarly, mortality also varied in children categorized by a range of laboratory characteristics (Table 3). The case fatality rate (CFR)-the proportion of children who died in hospital-was $19.5 \%$ in children with severe anaemia and as a consequence this complication was a major contributor to overall mortality $(33 / 63 ; 52.4 \%)$. As median lactate was significantly higher in children who died $(5.6 \mathrm{mmol} / \mathrm{L}$; IQR 2.6-9.4) than in those who survived $(2.1 ; 1.7-3.6)$ $(P=0.004)$, hyperlactataemia was strongly associated with mortality $(\mathrm{P}<0.0001)$. Hypoglycaemia was also associated with mortality $(P<0.001)$, but no correlation was found between admission parasite density and outcome. In general, CFRs increased with the number of severity features reported (Fig. 1). While a number of clinical and laboratory features were associated with outcome on univariate analysis (Tables 2 and 3), the only features that remained significant on multivariate analysis were severe anaemia $(P=0.0002)$, hypoxaemia $(P=0.008)$, hyperlactataemia $(P=0.001)$ and hepatomegaly $(P=0.004)$ (Table 4).

\section{Discussion}

To the best of our knowledge, this study is the first to describe the clinical and laboratory features of childhood severe $P$. falciparum malaria in Eastern Uganda that follows the standard WHO criteria [12]. Moreover, the sample size was large in comparison with similar earlier studies conducted elsewhere $[4,5,19]$ and to a recent study conducted in Kampala, Central Uganda [20]. The median age of the children recruited was 18 months and the majority were $<5$ years old. The common clinical features recorded were respiratory distress, clinical jaundice, severe anaemia, hyperlactataemia and the recent passage of dark red or black urine. The overall case fatality rate was high $(9.5 \%)$ and increased with the number of clinical manifestations recorded.

In the current case-series, $14 \%$ of children reported a history of having recently passed dark red or black urine, consistent with the diagnosis of haemoglobinuria or blackwater fever. This figure is close to the $14.5 \%$ previously reported among children recruited to the FEAST trial at the MRRH site [7]. While the entry criteria for 
Table 2 Clinical and demographic characteristics of the study population stratified by survival status

\begin{tabular}{|c|c|c|c|c|}
\hline Variable & Overall, N (\%) & Survivors N (\%) & Deaths N (\%) & $P$ value \\
\hline Number & 662 & 599 & 63 & - \\
\hline \multicolumn{5}{|l|}{ Age } \\
\hline Median age (months; IQR) & $18(10-33)$ & $18(10-33)$ & $18(9-29)$ & 0.67 \\
\hline \multicolumn{5}{|l|}{ Gender } \\
\hline Male & $382 / 662(57.7)$ & $343(57.2)$ & 39 (61.9) & 0.48 \\
\hline \multicolumn{5}{|l|}{ Clinical symptoms } \\
\hline Fever in this illness & $648 / 662(98.0)$ & $586(97.8)$ & $62(98.4)$ & 0.76 \\
\hline Cough & 130/662 (19.6) & $121(20.2)$ & $9(14.2)$ & 0.26 \\
\hline Vomiting & $266 / 662(40.2)$ & $242(40.4)$ & $24(38.0)$ & 0.72 \\
\hline Diarrhoea & 238/662 (36.0) & $214(35.7)$ & $24(38.0)$ & 0.71 \\
\hline Convulsions ${ }^{\mathrm{b}}$ & $147 / 662(22.2)$ & $123(20.5)$ & $24(38.0)$ & 0.001 \\
\hline Red or cola-coloured urine & $93 / 662(14.0)$ & $81(13.5)$ & $12(19.0)$ & 0.23 \\
\hline \multicolumn{5}{|l|}{ Clinical signs } \\
\hline \multicolumn{5}{|l|}{ General } \\
\hline Pyrexia $\left(>37.5^{\circ} \mathrm{C}\right)$ & $411 / 662(62.1)$ & $380(63.4)$ & $31(49.2)$ & 0.027 \\
\hline Hyperpyrexia $\left(\geq 40.0^{\circ} \mathrm{C}\right)$ & $55 / 662(8.3)$ & $47(7.8)$ & $8(12.6)$ & 0.81 \\
\hline Hypothermia $\left(<36.0^{\circ} \mathrm{C}\right)$ & $11 / 662(1.7)$ & $10(1.6)$ & $1(1.6)$ & 0.96 \\
\hline Pallor & $338 / 662(51.1)$ & $293(48.9)$ & $45(71.4)$ & 0.001 \\
\hline Clinical jaundice & $177 / 662(26.7)$ & $156(26.0)$ & $21(33.3)$ & 0.21 \\
\hline \multicolumn{5}{|l|}{ Respiratory system } \\
\hline Respiratory distress & $554 / 662(83.7)$ & $501(83.6)$ & $53(84.1)$ & 0.92 \\
\hline Hypoxaemia $\left(\mathrm{SpO}_{2}<92 \%\right)$ & 49/662 (7.4) & $35(5.8)$ & $14(22.2)$ & $<0.0001$ \\
\hline \multicolumn{5}{|l|}{ Cardiovascular/hydration } \\
\hline Severe tachycardia ${ }^{a}$ & $291 / 629(46.2)$ & $267 / 570(46.8)$ & $24(40.6)$ & 0.37 \\
\hline Temperature gradient & 251/662 (37.9) & $222(37.0)$ & $29(46.0)$ & 0.16 \\
\hline Capillary refill time $>2$ secs & 135/662 (20.4) & $114(19.0)$ & $21(33.3)$ & 0.007 \\
\hline Weak pulse & $23 / 662(3.5)$ & $20(3.3)$ & $3(4.7)$ & 0.56 \\
\hline Sunken eyes (dehydration) & $66 / 634(10.4)$ & $58 / 573(10.1)$ & $8 / 61(13.1)$ & 0.47 \\
\hline \multicolumn{5}{|l|}{ Abdominal } \\
\hline Splenomegaly (>2 cm) & 247/662 (37.3) & $216(36.0)$ & $31(49.2)$ & 0.04 \\
\hline Hepatomegaly (> $2 \mathrm{~cm}$ ) & 228/662 (34.4) & $197(32.8)$ & $31(49.2)$ & 0.009 \\
\hline \multicolumn{5}{|l|}{ Neurological } \\
\hline Impaired consciousness & $52 / 662(7.9)$ & $43(7.1)$ & $9(14.2)$ & 0.046 \\
\hline Prostration & $43 / 662(6.5)$ & $37(6.1)$ & $6(9.5)$ & 0.31 \\
\hline Coma & $9 / 662(1.4)$ & $6(1.0)$ & $3(4.7)$ & 0.014 \\
\hline
\end{tabular}

With the exception of age, figures represent numbers with column percentages in parentheses. Denominators are indicated where data are missing; splenomegaly and hepatomegaly were measured from the costal margin in the mid-clavicular line

a defined as $>180$ beats per min in children younger than 12 months of age, $>160$ beats per min in children 1 to 5 years of age, or $>140$ beats per minute in children older than 5 years of age

b > 2 in 24 h; P-values between survivors and deaths were estimated by $\mathrm{X}^{2}$ tests with the exception of age, which was compared by the Kruskal-Wallis test

recruitment to that study-severe febrile illness with impaired perfusion-were different from those in the current study, the similarly high prevalence confirms the current importance of this condition in Eastern Uganda. Although historically, the passage of dark urine has not been reported frequently among children, a growing number of case-series have been published in recent years that have described this problem in both Africa
[14-16, 21, 22] and Oceania [23]. Many previous reports have been based on the subjective reporting of urine colour by patients, parents or guardians, as recommended by the WHO. In this study, however, in addition to such reports urine colour was also corroborated by asking the parents to match the colour of their child's urine to the corresponding colour on the Hillmen urine colour scale [13]. Additionally, samples collected after admission were 


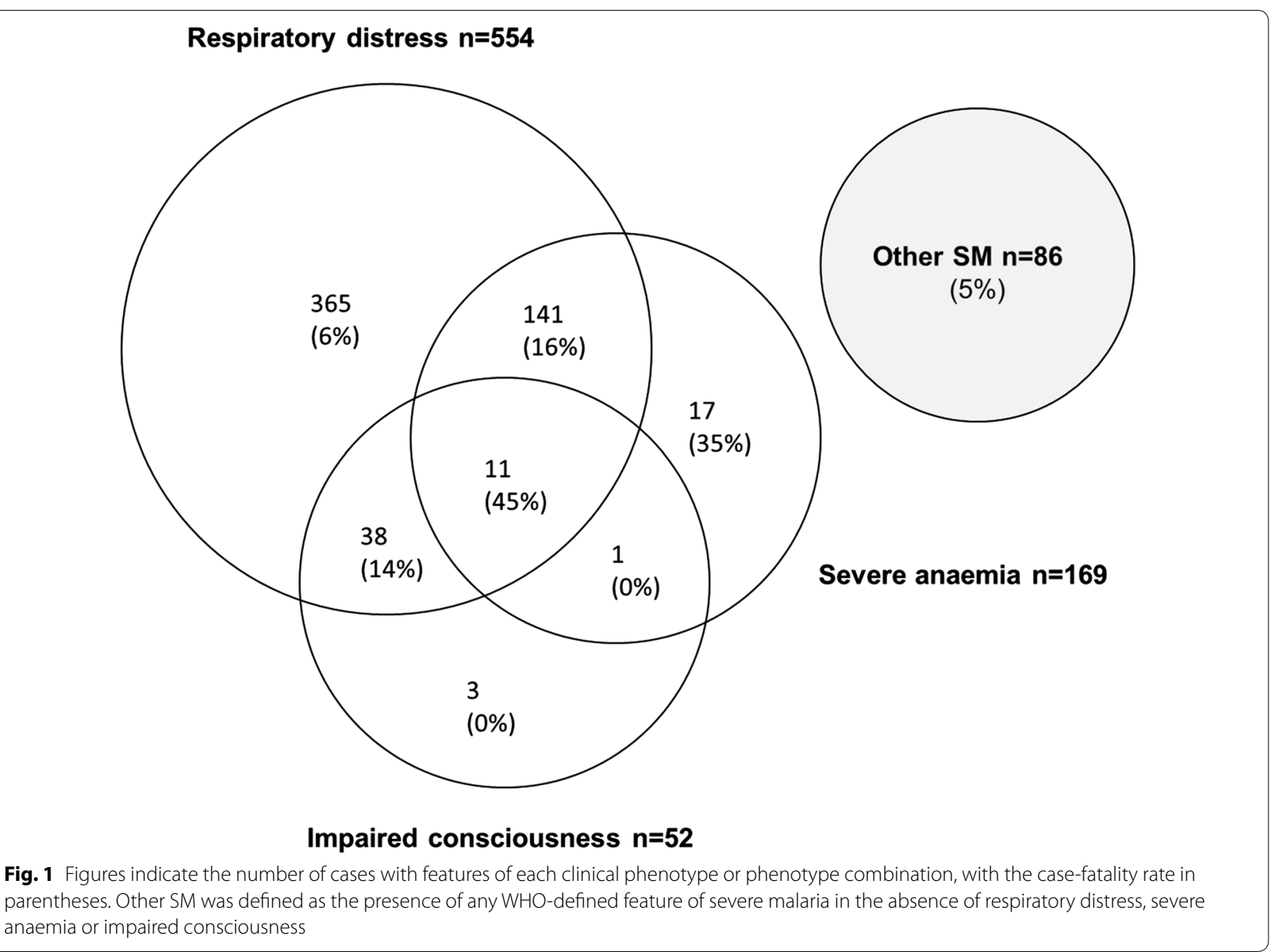

Table 3 Laboratory parameters among patients, stratified by survival status

\begin{tabular}{|c|c|c|c|c|}
\hline Laboratory parameter & Overall, $\mathrm{N}(\%)$ & Survivors (\%) & Deaths (\%) & P-value \\
\hline Number & 662 & 599 & 63 & $\mathrm{n} / \mathrm{a}$ \\
\hline \multicolumn{5}{|l|}{ Parasitaemia } \\
\hline Geometric mean (parasites $/ \mu \mathrm{L} ; 95 \% \mathrm{Cl}$ ) & $58800(49700-69600)$ & $61110(51$ 100-73 000) & $41390(25060-68$ 300) & 0.078 \\
\hline Hyperparasitaemia $^{\text {b }}$ & $365 / 585(62.4)$ & $331 / 558(62.6)$ & $34 / 57(59.6)$ & 0.65 \\
\hline \multicolumn{5}{|l|}{ Biochemistry } \\
\hline Median Lactate (mmol/L; IQR) & $2.2(1.7-4.0)$ & $2.1(1.7-3.6)$ & $5.6(2.6-9.3)$ & 0.004 \\
\hline Hyperlactataemia ( $\geq 5 \mathrm{mmol} / \mathrm{L}$ ) & $134 / 660(20.3)$ & 100/597 (16.6) & $34 / 63(53.9)$ & $<0.0001$ \\
\hline Median blood glucose (mmol/L; IQR) & $6.8(5.5-8.4)$ & $6.8(5.5-8.4)$ & $7.4(5.2-10.0)$ & 0.24 \\
\hline Hypoglycaemia (<2.2 mmol/L) & $21 / 577(3.6)$ & $15 / 527(2.8)$ & $6 / 50(12.0)$ & 0.004 \\
\hline \multicolumn{5}{|l|}{ Haematology } \\
\hline Median Haemoglobin (g/dL; IQR) & $7.1(4.9-10.1)$ & $8.0(5.1-10.1)$ & $4.8(3.3-9.7)$ & $<0.0001$ \\
\hline Severe anaemia $(\mathrm{Hb}<5 \mathrm{~g} / \mathrm{dL})$ & $169 / 662(25.5)$ & $136(22.7)$ & $33(52.3)$ & $<0.0001$ \\
\hline Leucocytosis $^{c}$ & $176 / 632(27.8)$ & 152/571(26.6) & 24/61 (39.3) & 0.035 \\
\hline Thrombocytopaenia $^{\mathrm{d}}$ & 263/632 (41.6) & $237 / 571(41.5)$ & $26 / 61(42.6)$ & 0.87 \\
\hline
\end{tabular}

Figures show N's with proportions in parentheses

${ }^{a} \mathrm{n}=585, \mathrm{Cl}$ confidence interval, IQR interquartile range; P-values were estimated by $\mathrm{X}^{2}$ tests for categorical and Student's $t$-tests for continuous variables

b as defined in Table 1

c white blood cell count $>11 \times 10^{3}$ cells $/ \mathrm{mm}^{3}$

d platelet count $<150 \times 10^{3} / \mu \mathrm{L}$ 
Table 4 Logistic regression analysis for predictors of mortality

\begin{tabular}{|c|c|c|c|c|}
\hline \multirow[t]{2}{*}{ Variable } & \multicolumn{2}{|c|}{ Univariate logistic regression } & \multicolumn{2}{|c|}{ Multivariate logistic regression } \\
\hline & Odds ratio $(95 \% \mathrm{Cl})$ & $P$-value & Odds ratio $(95 \% \mathrm{Cl})$ & $P$-value \\
\hline \multicolumn{5}{|l|}{ Clinical } \\
\hline Pyrexia & $0.56(0.33-0.94)$ & 0.027 & $0.79(0.40-1.57)$ & 0.50 \\
\hline Pallor & $2.61(1.48-4.61)$ & 0.001 & $0.84(0.34-2.12)$ & 0.98 \\
\hline Coma & $4.94(1.20-20.2)$ & 0.01 & $1.52(0.28-8.23)$ & 0.62 \\
\hline Delayed capillary refill & $2.13(1.21-3.73)$ & 0.007 & $0.82(0.35-1.93)$ & 0.64 \\
\hline Splenomegaly & $1.72(1.02-2.89)$ & 0.040 & $1.00(0.46-2.18)$ & 0.75 \\
\hline Hepatomegaly & $1.98(1.17-3.33)$ & 0.009 & $2.29(1.29-4.06)$ & 0.004 \\
\hline Hypoxaemia & $4.60(2.32-9.13)$ & $1.25 \times 10^{-5}$ & 3.64 (1.39-9.52) & 0.008 \\
\hline \multicolumn{5}{|l|}{ Laboratory } \\
\hline Severe anaemia & $3.74(2.20-6.36)$ & $1.05 \times 10^{-6}$ & $5.36(2.16-1.32)$ & 0.0002 \\
\hline Hyperlactataemia & $5.83(3.40-9.50)$ & $1.58 \times 10^{-7}$ & $3.66(1.72-7.80)$ & 0.001 \\
\hline Hypoglycaemia & $3.84(1.44-10.19)$ & 0.004 & 2.25 (0.63-7.98) & 0.21 \\
\hline Leucocytosis & $1.79(1.04-3.09)$ & 0.035 & $1.03(0.49-2.14)$ & 0.93 \\
\hline
\end{tabular}

verified against this scale by attending clinicians. While the lack of systematic urine testing is a weakness of the study, the use of the colour scale adds to the veracity of the reported data. Unlike descriptions from Nigeria [16] and the Democratic Republic of Congo [22], none of the children presenting with dark urine in the current study gave a history suggestive of acute renal failure, although subclinical renal impairment cannot be excluded on the basis of clinical history alone. Both the aetiology of dark urine and the reasons for its more recent increase among children with malaria in Africa are incompletely understood, but we have previously suggested that it might be related to the recent policy change towards the use of artemisinin-based combination therapy (ACT) as firstline treatments of malaria [7]. Further work examining this subject is ongoing.

Notable was the high proportion of children who presented with respiratory distress. Respiratory distress in children with severe malaria can be categorized into two major components: deep breathing, which involves an abnormally increased amplitude of chest excursion, and indrawing (or nasal flaring in younger children), often associated with an increased rate of breathing [24]. Deep breathing has been found to correlate closely with the presence of acidosis in previous studies [25] while chest indrawing is often a sign of lung parenchymal disease, including pneumonia [24]. Both components are included in the WHO definitions of severe malaria [12, 24]. In the current study, data regarding the individual components of respiratory distress were not recorded separately, but the fact that the correlation between respiratory distress and acidosis was low suggests that parenchymal disease may have been present in a high proportion of recruited cases. Previous studies have suggested that lung disease is a less common manifestation of severe malaria than deep breathing [25], raising the possibility that malaria may not have been the primary cause of severity in a proportion of children recruited to the current study, highlighting the difficulties in phenotyping children based on clinical evidence alone.

In keeping with the local epidemiology of heavy perennial malaria transmission [26], severe malarial anaemia was significantly more common than cerebral malaria in the current case-series. The spectrum differed markedly from that reported from areas of lower transmission, where neurological manifestations in older patients predominate [2, 3]. For example, in one study, conducted in Kampala, Uganda, children with cerebral malaria were significantly older (median 2.5 years, IQR $=1.5-3.9$ years) than children without cerebral malaria $(1.7$ years, IQR $=1.0-2.9$ years; $P<0.0001)[20]$. The case fatality rate in cerebral malaria is generally high with studies typically reporting rates that range between 10 and $40 \%$ [2, 27, 28]. In the AQUAMAT trial [29], even in children who were treated with artesunate mortality exceeded $20 \%$ in those with profound coma (BCS $\leq 2$ ), a figure that is broadly consistent with that seen in our current study. Although not measured in this study, long-term neurological sequelae are common in children admitted with cerebral malaria [30], potentially resulting from recurrent convulsions, hypoglycaemia and acidosis $[2,6]$.

In contrast to the recent mortality rates reported from the TRACT trial [31, 32], which examined blood transfusion strategies in multiple settings (including two centres from Eastern Uganda), inpatient mortality 
among children presenting with severe malarial anaemia in the current observational study was high (19.5\%). The lower mortality seen in TRACT might have reflected the fact that recruitment to the trial was halted when blood for transfusion was not available or because of improvements in blood transfusion services in Uganda during the intercurrent period. In the current study, the receipt of blood transfusions was not recorded; however, a high rate of early mortality among critically sick children with severe anaemia while awaiting a blood transfusion has been previously described [33]. The importance of adhering to the restrictive blood transfusion policy from the WHO was underpinned by evidence from children with severe and uncomplicated anaemia within TRACT [31], who did not require immediate transfusion, allowing donor blood to be targeted to those with severe and complicated anaemia in situations where supplies are limited.

In conclusion the common clinical features of severe $P$. falciparum malaria among children in the current caseseries were respiratory distress, clinical jaundice and severe anaemia. Clinical jaundice and the recent passage of dark red or black urine, neither of which have been commonly reported in similar studies from other parts of Africa, were frequent. Overall mortality was high, with severe anaemia, hyperlactataemia, hypoxaemia and hepatomegaly being independently associated with death. Observations from this study justify further work aimed at investigating the causes and best treatment for blackwater fever in children in Eastern Uganda.

\section{Acknowledgements}

We acknowledge all staff and patients at MRRH and the MCRI for their contributions to this work.

\section{Authors' contributions}

PO conceived the study and wrote the first draft of the manuscript. PO, JN, MC and TS collected the data. GN and CN designed the database and conducted the data analysis, AM, SU and RM conducted laboratory analyses. CE, CK, KM and TNW supervised the study. All authors contributed to editing the paper approved the final submission. All authors read and approved the final manuscript.

\section{Funding}

This study was funded through an award to the KEMRI-Wellcome Trust Research Programme from the Wellcome Trust (IDeAL, Wellcome Trust, Strategic Award) and by Wellcome Trust Senior Fellowships to TNW (202800 and 091758).

\section{Availability of data and materials}

The study data are available by request to the corresponding author.

\section{Ethics approval and consent to participate}

The study was approved by both the Mbale Regional Referral Hospital Research and Ethics Committee and Uganda National Council for Science and Technology, while local permission to conduct the study was obtained from Director of the Mbale Regional Referral Hospital. The study conformed to the provisions of ethical standards in Uganda.

\section{Consent to publish}

The Mbale Clinical Research Institute (MCRI, www.mcri.ac.ug), a research entity affiliated to the Uganda National Health Research Organization, approved the publication of this manuscript.

\section{Competing interest}

The authors declare no conflict of interest.

\begin{abstract}
Author details
${ }^{1}$ Faculty of Health Sciences, Busitema University, Mbale Campus, P.O. Box 1460, Mbale, Uganda. ${ }^{2}$ Mbale Clinical Research Institute, P.O. Box 1966, Mbale, Uganda. ${ }^{3}$ Soroti Regional Referral Hospital, P.O. Box 289, Soroti, Uganda. ${ }^{4}$ KEMRI-Wellcome Trust Research Programme, Centre for Geographic Medicine Research-Coast, Kilifi, Kenya. ${ }^{5}$ Makerere University College of Health Sciences, P.O. Box 7072, Kampala, Uganda. ${ }^{6}$ Institute of Global Health Innovation, Imperial College, Medical School Building St Mary's Campus, Imperial College, London W2 1PG, UK.
\end{abstract}

Received: 15 June 2020 Accepted: 25 August 2020

Published online: 03 September 2020

\section{References}

1. World Health Organization, World Malaria Report 2019 [https://www. who.int/publications/i/item/world-malaria-report-2019].

2. Idro R, Aloyo J. Manifestations, quality of emergency care and outcome of severe malaria in Mulago Hospital. Uganda Afr Health Sci. 2004;4:50-7.

3. Idro R, Aloyo J, Mayende L, Bitarakwate E, John CC, Kivumbi GW. Severe malaria in children in areas with low, moderate and high transmission intensity in Uganda. Trop Med Int Health. 2006;11:115-24.

4. Marsh K, Forster D, Waruiru C, Mwangi I, Winstanley M, Marsh V, et al. Indicators of life-threatening malaria in African children. N Engl J Med. 1995;332:1399-404

5. Imbert P, Gerardin P, Rogier C, Ka AS, Jouvencel P, Brousse V, et al. Severe falciparum malaria in children: a comparative study of 1990 and 2000 WHO criteria for clinical presentation, prognosis and intensive care in Dakar, Senegal. Trans R Soc Trop Med Hyg. 2002;96:278-81.

6. Idro R, Kakooza-Mwesige A, Balyejjussa S, Mirembe G, Mugasha C, Tugumisirize J, et al. Severe neurological sequelae and behaviour problems after cerebral malaria in Ugandan children. BMC Res Notes. 2010;3:104.

7. Olupot-Olupot P, Engoru C, Uyoga S, Muhindo R, Macharia A, Kiguli S, et al. High frequency of blackwater fever among children presenting to hospital with severe febrile illnesses in Eastern Uganda. Clin Infect Dis. 2017;64:939-46.

8. Kilama M, Smith DL, Hutchinson R, Kigozi R, Yeka A, Lavoy G, et al. Estimating the annual entomological inoculation rate for Plasmodium falciparum transmitted by Anopheles gambiae s.l. using three sampling methods in three sites in Uganda. Malar J. 2014.13:111.

9. Okiro EA, Alegana VA, Noor AM, Snow RW. Changing malaria intervention coverage, transmission and hospitalization in Kenya. Malar J. 2010;9:285.

10. Okiro EA, Kazembe LN, Kabaria CW, Ligomeka J, Noor AM, Ali D, Snow RW. Childhood malaria admission rates to four hospitals in Malawi between 2000 and 2010. PLOS ONE. 2013;8:e62214.

11. Roca-Feltrer A, Carneiro I, Smith L, Schellenberg JR, Greenwood B, Schellenberg D. The age patterns of severe malaria syndromes in sub-Saharan Africa across a range of transmission intensities and seasonality settings. Malar J. 2010;9:282.

12. World Health Organization, Communicable Diseases Cluster. Severe falciparum malaria. Trans R Soc Trop Med Hyg. 2000;94 Suppl 1:S1-90.

13. Hillmen P, Hall C, Marsh JC, Elebute M, Bombara MP, Petro BE, et al. Effect of eculizumab on hemolysis and transfusion requirements in patients with paroxysmal nocturnal hemoglobinuria. N Engl J Med. 2004;350:552-9.

14. Kunuanunua TS, Nsibu CN, Gini-Ehungu JL, Bodi JM, Ekulu PM, Situakibanza $\mathrm{H}$, et al. [Acute renal failure and severe malaria in Congolese children living in Kinshasa, Democratic Republic of Congo](in French). Nephrol Ther. 2013;9:160-5.

15. Bodi JM, Nsibu CN, Longenge RL, Aloni MN, Akilimali PZ, Tshibassu PM, et al. Blackwater fever in Congolese children: a report of clinical, laboratory features and risk factors. Malar J. 2013;12:205. 
16. Ajetunmobi WA, Orimadegun AE, Brown BJ, Afolabi NK, Olabiyi FA, Anetor $J$, et al. Haemoglobinuria among children with severe malaria attending tertiary care in Ibadan Nigeria. Malar J. 2012;11:336.

17. Gobbi F, Audagnotto S, Trentini L, Nkurunziza I, Corachan M, Di Perri G. Blackwater fever in children Burundi. Emerg Infect Dis. 2005;11:1118-20.

18. Westwood A, Buys H, Cheema B. An adapted triage tool (ETAT) at Red Cross War Memorial Children's Hospital Medical Emergency Unit, Cape Town, South Africa: an evaluation. S Afr Med J. 2013;103:273.

19. Imbert P. [Criteria of severity in childhood falciparum malaria](in French) Arch Pediatr. 2003;10(Suppl 5):532s-8s.

20. Cserti-Gazdewich CM, Dhabangi A, Musoke C, Ssewanyana I, Ddungu H, Nakiboneka-Ssenabulya D, et al. Inter-relationships of cardinal features and outcomes of symptomatic pediatric Plasmodium falciparum malaria in 1,933 children in Kampala Uganda. Am J Trop Med Hyg. 2013;88:747-56.

21. Ahmed I, Olowe O. Haemoglobinuria in Nigerian children. Afr J Med Sci. 1971;2:101-8

22. Aloni NM, Nsangu M, Kunuanunua T, Kadima TB, Muanda TF. [Haemolytic crisis of blackwater fever following artemether-lumefantrine intake](in French). Bull Soc Pathol Exot. 2010:103:296-8.

23. O'Donnell A, Weatherall DJ, Taylor AM, Reeder JC, Allen SJ. Muscle cell injury, haemolysis and dark urine in children with falciparum malaria in Papua New Guinea. Trans R Soc Trop Med Hyg. 2006;100:817-25.

24. World Health Organization. Severe Malaria. Trop Med Int Health. 2014;19(Suppl):7-131.

25. English M, Waruiru C, Amukoye E, Murphy S, Crawley J, Mwangi I, et al. Deep breathing in children with severe malaria: indicator of metabolic acidosis and poor outcome. Am J Trop Med Hyg. 1996;55:521-4.

26. Snow RW, de Bastos Al, Lowe BS, Kabiru EW, Nevill CG, Mwankusye S, et al Severe childhood malaria in two areas of markedly different falciparum transmission in east Africa. Acta Trop. 1994:57:289-300.
27. Durrani AB, Durrani IU, Abbas N, Jabeen M. Epidemiology of cerebral malaria and its mortality. J Pak Med Assoc. 1997;47:213-5.

28. Armah HB, Wilson NO, Sarfo BY, Powell MD, Bond VC, Anderson W, et al. Cerebrospinal fluid and serum biomarkers of cerebral malaria mortality in Ghanaian children. Malar J. 2007:6:147.

29. von Seidlein L, Olaosebikan R, Hendriksen IC, Lee SJ, Adedoyin OT, Agbenyega T, et al. Predicting the clinical outcome of severe falciparum malaria in african children: findings from a large randomized trial. Clin Infect Dis. 2012:54:1080-90.

30. Dondorp AM, Fanello CI, Hendriksen IC, Gomes E, Seni A, Chhaganlal KD, et al. Artesunate versus quinine in the treatment of severe falciparum malaria in African children (AQUAMAT): an open-label, randomised trial. Lancet. 2010;376:1647-57.

31. Maitland K, Kiguli S, Olupot-Olupot P, Engoru C, Mallewa M, Saramago Goncalves $\mathrm{P}$, et al. Immediate transfusion in African children with uncomplicated severe anemia. N Engl J Med. 2019;381:407-19.

32. Maitland K, Olupot-Olupot P, Kiguli S, Chagaluka G, Alaroker F, Opoka RO, et al. Transfusion volume for children with severe anemia in Africa. $\mathrm{N} \mathrm{Engl}$ J Med. 2019;381:420-31.

33. Kiguli S, Maitland K, George EC, Olupot-Olupot P, Opoka RO, Engoru C, et al. Anaemia and blood transfusion in African children presenting to hospital with severe febrile illness. BMC Med. 2015;13:21.

\section{Publisher's Note}

Springer Nature remains neutral with regard to jurisdictional claims in published maps and institutional affiliations.
Ready to submit your research? Choose BMC and benefit from:

- fast, convenient online submission

- thorough peer review by experienced researchers in your field

- rapid publication on acceptance

- support for research data, including large and complex data types

- gold Open Access which fosters wider collaboration and increased citations

- maximum visibility for your research: over $100 \mathrm{M}$ website views per year

At BMC, research is always in progress.

Learn more biomedcentral.com/submissions 